Miralles i Monserrat, Joan: Veus del passat. Biblioteca Càtedra Unesco VI. Barcelona: Institut d'Estudis Catalans, 2019, $242 \mathrm{p}$.

\title{
Veus del passat
}

Montserrat SORONELlas MASDEU

Universitat Rovira i Virgili, Tarragona

El llibre de Joan Miralles, catedràtic emèrit de Filologia Catalana a la Universitat de les Illes Balears, és la publicació d'una etnografia iniciàtica d'un acadèmic que té una extensa i prolífica obra en diversos camps d'interès filològic i històric. És un llibre publicat l'any 2020 però que ens desplaça a finals de la dècada de I960, quan Joan Miralles era un jove investigador, acabat de llicenciar i ple de curiositat per interpretar la realitat més propera, la del seu poble, Montuïri, a l'illa de Mallorca, una realitat que començava a canviar molt de pressa. Miralles s'interessa per rescatar de l'oblit previsible maneres de fer, de relacionar-se, personatges de l'època, cultura popular i tota mena de relats sobre la història local que fins llavors havien estat quotidians però que ja començaven a caure en desús. Val a dir que l'autor demostra tenir una sensibilitat especial atès que l'any I969, quan fa les primeres entrevistes a persones de Montuïri, la societat encetava la transformació $i$, en aquest punt d'inici, el canvi encara no ha tingut temps de provocar reaccions potents que activin la voluntat ferma de retenir i patrimonialitzar el passat. Miralles, doncs, que és nascut l'any I945, no actua des de l'enyorança d'un passat idealitzat, sinó des de l'interès per retenir uns coneixements transmesos per tradició oral o per la mateixa pràctica, als quals ni la societat en abstracte ni les mateixes persones informants són capaces encara de donar valor. Amb les seves entrevistes, Miralles s'aboca a recollir una cultura que als montuïrencs d'ara els resulta llunyana i quasi exòtica, però que l'any ig69 encara era a tocar.

Veus del passat és un recull d'onze testimonis de persones residents a Montuïri, que Joan Miralles va recollir majoritàriament l'any I969 (hi ha dues entrevistes fetes els anys I978 i I979). Les onze persones, quatre dones i set homes, van fer un total de 2I sessions d'entrevista amb Miralles, la qual cosa ja és indicativa de la voluntat de l'entrevistador de fer una recollida exhaustiva i científica de les dades que tenia interès a recaptar. Val a dir que una de les persones entrevistades, Joan Grimalt Pocoví, Niu, va fer fins a vuit sessions d'entrevista amb Miralles, senyal inequívoc que, com veurem, es tractava d'un informant essencial per a alguns dels temes de recerca futurs de l'autor i una persona a la qual calia tornar i retornar per recollir les dades amb la major amplitud i fidelitat possible i fer-ho sense cansar-la en excés amb sessions llargues d'entrevista. Cadascuna de les persones entrevistades és identificada amb el nom, cognoms i amb el renom. L'ús del renom és indicatiu de l'interès i l'expertesa de Miralles en l'estudi de l'onomàstica, una de les seves especialitats de recerca.

Per fer reculls de memòria oral és indispensable dominar la tècnica de l'entrevista. Al llibre intuïm un Miralles entrevistador àvid d'obtenir la informació que busca, intuïtiu i també preparat, que demostra dominar el context de la informació que demana a les persones a qui entrevista. No ens ho explica, però es pot deduir de la manera com condueix les entrevistes i en les repeticions dels temes que tracta en cadascuna que Miralles va fer servir un guió que va utilitzar de manera flexible per tal que la persona entrevistada se sentís lliure per esplaiar-se en aque- 
lles qüestions del seu interès, però sense que l'entrevistador hagués de renunciar a l'obtenció de tota la informació que havia previst. Es nota, però, en algun moment de les entrevistes, algun petit pecat d'entrevistador jove i encara inexpert, en la manera com Miralles salta d'un tema a un altre. Hi ha un moment molt significatiu pel que fa a aquest tipus d'interrupcions, és el moment en què una de les informants, Aina Maria Oliver i Sastre, està relatant un episodi molt personal de la seva vida, la mort del seu marit, en què un Miralles jove i potser incomodat pel relat massa situat en la dimensió de les emocions canvia radicalment de tema i li pregunta: «Com va ser que va tenir telèfon?» Faig aquesta apreciació no com un demèrit, al contrari, sinó per reivindicar un dels valors del llibre: publicar la transcripció de les entrevistes és un exercici de valentia pel que implica de despullar-se com a investigador de la retòrica protectora de l'anàlisi científica que amaga les destreses o les errades que cometem en el procés del treball de camp. Miralles, com diu Joan A. Argenter en el seu pròleg, ens ha deixat entrar al seu Arxiu d'Història Oral, un espai que va començar a configurar ell mateix el I969, i que ara esdevé definitivament i radicalment públic en la mesura que el llibre ens dona accés a les transcripcions i també als àudios de les entrevistes mitjançant un codi QR que ens permet escoltar les veus dels personatges protagonistes del llibre. Quina manera tan generosa de retornar a Montuïri, a la seva gent i a les persones interessades, la riquesa de la informació recollida fa cinquanta anys.

Les entrevistes versen sobre temàtiques locals, les dimensions personals n'acostumen a ser absents, més enllà de recollir els noms de les persones entrevistades o alguna informació sobre l'ofici i la família. Són entrevistes centrades en la memòria col-lectiva. Miralles cerca preservar la memòria de la cultura popular i d'alguns episodis de la història local: les formes de sociabilitat, els mitjans de transport i la seva transformació, els balls, les glosses, la música popular, les rondalles, l'etnomedicina, la memòria de tempestes i epidèmies, el bandolerisme i el contraban, la bruixeria, la localització de possibles jaciments arqueològics, la transformació de les formes de treball amb l'arribada de la tecnologia, els personatges locals, els usos alimentaris i les formes de vestir, entre d'altres. Les entrevistes no tenen un perfil biogràfic, sinó que pregunten directament sobre la informació que és objecte de la cerca. Altre cop no estem davant d'una mancança, sinó d'una manera de fer que hem de situar també en un moment en què es donava menys valor al relat biogràfic, a la història de vida, com a context per interpretar la informació recollida.

A les notes a peu de pàgina, Miralles proporciona al lector informació precisa i erudita sobre les dades que van apareixent als relats. La informació sobre els noms de lloc i de persona és ampliada de manera oportuna a les notes al peu amb les dades de context, geogràfiques, històriques i lexicogràfiques que són necessàries per ser contextualitzades i interpretades. És així que el llibre depassa el simple recull d'uns relats que tenen gran valor etnogràfic, per tal de ser també un llibre d'història local, d'història de l'illa de Mallorca i de la seva riquesa lingüística i cultural. El llibre combina les diferents veus: la de l'etnògraf-entrevistador d'un jove Miralles; les de les persones informants, d'un valor incalculable pel fet que ens fan un relat que avui ja no podria ser recollit, i la veu d'un Miralles madur, acadèmic i investigador expert, que s'ha esforçat a completar la informació, a arrodonir-la, a voltes amb interpretació, a voltes proporcionant les dades de context que posen en valor les narratives. 
El llibre comença amb un pròleg també excel-lent de Joan A. Argenter, director de la Càtedra Unesco de Diversitat Lingüística, promotora de la publicació. A la introducció, l'autor ens aporta algunes notes històriques de Montuïri necessàries per contextualitzar els relats; també hi inclou els criteris de transcripció utilitzats, una informació essencial per entendre el rigor científic i acadèmic de l'obra. Al final de la introducció, Miralles esmenta les entrevistes i les classifica en funció de les temàtiques en les quals incideixen; faré servir aquesta classificació per ordenar la síntesi i el comentari dels relats recollits per Miralles.

En el primer grup, Miralles hi recull les persones entrevistades que l'autor defineix com a històries de vida individuals que proporcionen informació de la vida i l'entorn de les persones entrevistades. En aquest punt, ja m'hi he referit, discrepo de l'autor en el fet de classificar-les com a històries de vida. De fet, des del meu punt de vista, no ho són, són relats individuals que no versen sobre cap tema especial pel fet que són persones que no tenien un esdeveniment o una història singular per explicar, però que no deixen més testimoni de la seva vida que la resta de relats recollits en el llibre. El testimoni de Catalina Garau, Rostida, nascuda l'any I877, és un testimoni excepcional d'una dona pagesa, de condició humil, que en el moment de ser entrevistada ja tenia 92 anys i que, per tant, havia viscut tota la seva vida en aquella societat mallorquina i en aquella cultura que començava a canviar tan i tan de pressa. El relat de Catalina és el primer del llibre i posa en evidència una dimensió de gènere i de classe que cal tenir molt en compte a l'hora d'escoltar aquestes veus. Catalina no ha anat enlloc gairebé fora de Montuïri i relata una vida de dona pagesa a la Mallorca rural de la primera meitat del segle xx. Una vida senzilla centrada en la feina i la família i bona coneixedora de la gent del lloc i de les seves activitats. El matrimoni format per Miquel Cerdà, Lloret, i Catalina Ribas, Rovegona, s'estenen més que la primera informant en les explicacions de les dades que els demana Miralles. Tots dos relaten la transformació del mitjans de transport, recorden qui va tenir la primera bicicleta o qui va dur el primer cotxe a Montuïri. Miquel relata més les feines del camp, mentre que Catalina s'esplaia en les explicacions sobre els menjars, les sociabilitats del temps d'oci i recorda cançons i glosses. Joan Fornés, Mora, pagès i bon coneixedor del terme, s'endinsa en explicacions de llocs que amplien els coneixements toponímics de l'autor, però l'entrevista està més centrada a localitzar restes arqueològiques trobades per l'informant treballant al camp.

Al segon grup en què Miralles classifica les entrevistes, només hi ha una història, la d'Aina Maria Oliver, de Meià. Aquest és el relat que aporta més informació personal. La història d'Aina Maria té molt d'interès, tot i que no s'hi aprofundeix: es va casar per poders l'any I9I5 amb un convilatà, metge de professió, que vivia a Mendoza, Argentina, una època de migració de mallorquins cap a Bons Aires. Miralles centra el relat d'Aina Maria en un episodi precisament relacionat amb el seu casament per poders, atès que en el seu viatge en vaixell a l'Argentina per reunir-se amb el seu marit va coincidir amb Josep Carner, que li va dedicar un poema que va ser publicat: La casadita de Montuïri. Aina Maria, però, preguntada per Miralles sobre aquesta qüestió, va pinzellant el seu relat amb informació sobre la seva estada a l'Argentina, el difícil retorn a Muntuïri amb dos infants i l'espòs malalt de grip el I9I8, una malaltia que els va provocar molt de patiment i de la qual va acabar morint l'any I924. El relat d'Aina Maria, amb una posició social que s'intueix més elevada que la de la resta d'informants, està fet des d'una mirada diferent sobre la societat montuïrienca, profundament marcada pel gènere i la classe social. 
Les vuit entrevistes a Joan Grimalt i Pocoví, Niu, configuren el tercer grup amb què Miralles classifica els testimonis del llibre. El fet de retornar a un informant fins a vuit vegades ja és indicatiu que l'autor tenia un interès especial en aquest testimoni. D'altra banda, cal tenir en compte que Grimalt és un bon informant, en el sentit que domina el relat, s'esplaia en explicacions i que sembla sentir-se còmode en el rol d'informant. Joan Grimalt havia estat músic, fobioler, i la seva entrevista, malgrat que va a tocar tots els temes de memòria local que Miralles tenia previstos, es focalitza a recollir la seva experiència i els seus coneixements al voltant dels cossiers, els balls populars singulars de Montuïri i que Miralles ha treballat i documentat profusament en altres publicacions. Grimalt deu haver estat probablement un dels testimonis excepcionals amb què l'autor ha pogut documentar els cossiers i la cultura popular d'arrel tradicional montuïrenca, d'aquí ve la profusió de sessions d'entrevista amb aquest informant. Dues de les entrevistes són fetes el I978, nou anys després de les primeres i, en les més recents, es nota un major llibertat de Grimalt en les explicacions relacionades amb els fets de la Guerra Civil. Al relat dels anys seixanta no hi ha al-lusions a la pròpia filiació política, no hi és al relat de Joan Grimalt ni tampoc al relat de cap dels altres informants, malgrat que en algun moment es fa alguna referència a la Guerra Civil i a la Falange, per exemple. Al relat del I978, en canvi, Grimalt no té inconvenient a afirmar la seva major vinculació al bàndol republicà en el moment del conflicte.

Per acabar, Miralles configura un grup d'entrevistes que ell va adreçar a recollir informació sobre una història familiar que vincula l'origen del descobridor Cristòfor Colom, i de Joanot Colom, líder de la revolta de les Germanies, a Montuïri. Les entrevistes que indaguen sobre aquesta qüestió són la de Rosa Pocoví, des Puig Moltó; la d'Antoni Lladó, Miró; la de Gabriel Sastre, Pellusco, i les de Rafel i Bartomeu Bauzà i Socies, Rafela. Els tres primers testimonis esmentats són breus i van encaminats quasi exclusivament a reunir informació sobre l'existència d'un arxiu familiar a can Rafela, la família suposadament descendent dels dos Colom esmentats, amb documentació que pogués testimoniar la veracitat del relat transmès de generació en generació. L'entrevista de Bartomeu Bauzà, en canvi, és el relat directe d'un secret familiar transmès de pares a fills durant centúries i que situa Cristòfor Colom en la figura de Joan Colom — que s'hauria canviat el nom-, germà de Tomeu Colom, procedents d'una família notable que travessava per certes dificultats a les darreries del segle xv i que van portar els Colom a emparar-se en l'anonimat. Una història fantàstica que, a manca de proves fefaents, queda en consideració de rondalla, a punt sempre per alimentar la imaginació popular.

Tanca el llibre un recull fotogràfic que ajuda el lector a situar-se en el context espai-temps.

Aquest llibre excel-lent desperta les veus del passat que, l'any 202I, són encara més reculades en el temps. La riquesa lèxica i de significats, i poder escoltar la fonètica, la melodia i l'expressivitat de la parla local de fa cinquanta anys és veritablement emocionant. Els testimonis que va escoltar i recollir Joan Miralles ja no hi són, totes les persones que van aportar els seus coneixements i experiències han desaparegut, però ara tenim l'oportunitat d'escoltar-los, de llegir-los sota la sàvia tutela acadèmica de l'autor. Són relats d'història oral, que és alhora local i universal. Amb referència a aquesta dualitat, tanco aquesta ressenya amb una dita que recorda almenys un parell de les persones que aporten la seva veu al llibre: «Tot el món és món menos Montuïri». 